\title{
Climate justice and cultural sustainability: The case of Etëtung (Vanuatu Women's Water Music)
}

\author{
Catherine Grant \\ Queensland Conservatorium Griffith University
}

\begin{abstract}
This is an author-produced PDF of an article published in The Asia Pacific Journal of Anthropology. Copyright Taylor and Francis. Citation information:

Grant, Catherine (2019). Climate justice and cultural sustainability: The case of Etëtung (Vanuatu Women's Water Music). The Asia Pacific J ournal of Anthropology 20(1): 42-56. https://doi.org/10.1080/14442213.2018.1529194
\end{abstract}

\begin{abstract}
This article investigates connections between climate justice and cultural sustainability through the case of Etëtung, or 'Vanuatu Women's Water Music', as it is found in the ni-Vanuatu community of Leweton. Drawing on existing literature, interviews and field visit observations, I consider how and why Etëtung is proving increasingly important in local efforts toward cultural sustainability and climate justice (social justice as it relates to climate change). Specifically, I focus on three ways in which community members are employing the practice of Etëtung to progress both climate justice and cultural sustainability concerns: first, through the use of Etëtung to maintain and transmit cultural and environmental knowledge; second, through featuring Etëtung in cultural tourism; and third, through drawing on Etëtung to enable greater participation in the regional and international climate change discourse. As such, this article presents and reflects on one multifaceted approach to advancing dual cultural sustainability and climate justice interests, with potential relevance to other contexts in the Pacific and beyond.
\end{abstract}

\section{Keywords}

climate change, cultural sustainability, music sustainability, social justice, Vanuatu, water music

In March 2015, Tropical Cyclone Pam ravaged Vanuatu, destroying up to $90 \%$ of infrastructure in the worst affected areas and leaving two thirds of the population in need of urgent humanitarian assistance (UNICEF 2016). Vanuatu falls in the path of tropical cyclones for several months of the year, and its population has been dealing with them for generations (Warrick 2009, 78). No other city in the world is at greater risk from natural disasters, including cyclones, than Vanuatu's capital city Port Vila (Verisk Maplecroft 2015), and climate change is set to increase both the frequency and severity of such extreme weather events (IPCC 2007).

The threats posed by climate change, however, go well beyond the direct risk of natural disasters. Climate change is already creating serious socioeconomic and health challenges for people in Vanuatu. Tourism and primary industries (especially agriculture, forestry, and fisheries) account for more than half of the country's Gross Domestic Product (IPCC 1997; Spickett, Katscherian and McIver 2013), and many ni-Vanuatu people rely on natural resources for employment, as well as for daily subsistence (Tanguay 2015). Climate change is adversely affecting those natural resources in diverse ways, including through coastal erosion, intrusion of saltwater into land and freshwater ecosystems, damage to coral reefs, landslides brought about by more 
intense and prolonged rainfall, and greater severity and incidence of flooding and drought (Republic of Vanuatu 2007; Klint et al. 2012). As those resources are damaged, livelihoods are jeopardised.

In Vanuatu as elsewhere, poverty, food insecurity, scarce water resources, and low infrastructure are exacerbating, and being exacerbated by, the socioeconomic effects of climate change (IPCC 2007). Greater exposure to heat waves, fires, floods, and cyclones has health implications for local populations, as do the less direct effects of climate change, such as poorer water quality and food production, less stable food supply, greater incidence of disease, and increasing population dispersal (Spickett, Katscherian and McIver 2013). Water- and food-borne disease outbreaks resulting from climate change present 'extreme' levels of risk to the people of Vanuatu, and vector-borne diseases (like malaria and dengue fever), malnutrition and food insecurity, non-communicable diseases, and temperature-related illnesses all present 'high' levels of risk (Spickett, Katscherian and McIver 2013, 48). It is perhaps not surprising that former Secretary General of the United Nations Bang Ki-Moon held that 'no other challenge in the Pacific is as urgent and potentially life threatening as climate change' (in Richmond and Sovacool 2012, 843).

Many scholars have argued that culture and cultural practices may play an important and unique role in mitigating and adapting to climate change (Hackmann, Moser and St. Clair 2014; Corner, Markowitz and Pidgeon 2014; Adger et al 2013). In this article, as a way to reflect on the multifaceted relationships between cultural sustainability, the natural environment, and climate change, I profile the performance practice of Etëtung (or 'Vanuatu Women's Water Music') in one ni-Vanuatu community, the Leweton Cultural Village. Drawing on interviews with community members and observations during a field visit in late 2017, as well as the handful of available published sources on Etëtung (Dick 2014, 2015; Dick \& Meltherorong 2011; Hayward 2014; Wessergo 2014), I consider how and why Etëtung is proving particularly influential in this community's efforts to maintain and promote its culture. I also consider how the community is drawing on this performance practice to foster greater local, regional, and even international understanding of the relationships between intangible culture, cultural sustainability and the natural environment. In this way, this article serves as a case study of how one community is progressing dual climate justice and cultural sustainability concerns, with potential relevance to other contexts in the Pacific and beyond.

\section{Leweton Cultural Village and the practice of Etëtung}

Leweton Cultural Village (henceforth 'Leweton') is a community of around twelve extended families on the island of Espiritu Santo, one of the 83 islands in the South Pacific that constitute the nation of Vanuatu. The village lies on the outskirts of Luganville (population c. 16,300), the second biggest city in Vanuatu. The families of Leweton come from the islands of Gaua and Merelava in the more remote north of the Vanuatu archipelago, in the south of the Banks Islands group (total population c. 8,500). Their relocation over time to the Luganville area may be understood as a part of the 'significant movement of people from various points of the archipelago to metropolitan areas' for education and/or employment, since independence from French-British colonial rule in 1980 (Hayward 2014). While some older residents of the Leweton community still speak to each other in Mwerlap, the indigenous language of Gaua and Merelava (spoken as a mother tongue by around 1,350 people; Simons and Fennig 2018), most residents converse with each other in Bislama, Vanuatu's lingua franca.

Following relocation to the Luganville area, the Mwerlap-speaking community continued to maintain kastom, 'a ni-Vanuatu term that roughly translates as "tradition" but with a strong sense of tradition being a living (rather than "museumified") set of practices' (Hayward 2014, 119). As in many ni-Vanuatu communities, however, the people of Leweton recognised that kastom was being 
affected by outside (Western) influences, the cash economy, and other changing ways of life. Senior cultural leaders began to consider the need for concerted approaches to preserving, promoting, and transmitting songs, stories, dances, and other kastom practices in their new location on Espiritu Santo. Instigated by these leaders, in the mid-2000s the Leweton community formalised into the Leweton Cultural Village. This strategic move was partly intended to enable and encourage the continued practice in the community, across all generations, of the language and cultural traditions of Gaua and Merelava, and partly to facilitate the livelihoods of the villagers through cultural tourism (Dick 2014). Playing a central role in the activities of the Leweton Cultural Village right from the start was the cultural practice Etëtung, known in English as 'Vanuatu Women's Water Music' (also 'liquid percussion' or 'water percussion'), in which a small group of girls and women stand in a circle or semicircle in waist-deep water and rhythmically slap its surface to create a diverse repertoire of rhythms and pitches (see Figure 1).

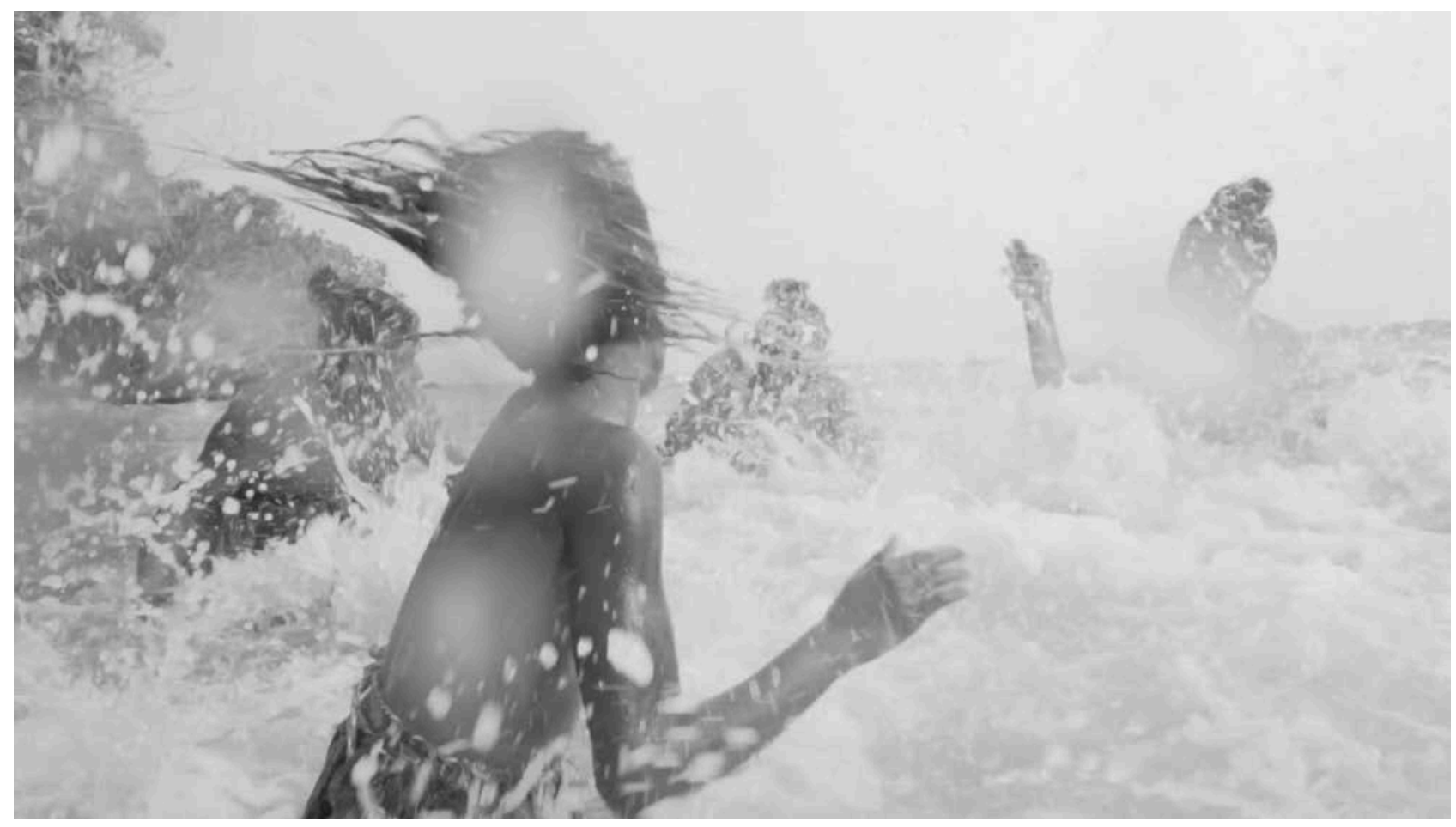

Figure 1. Etëtung performed by Leweton village members in coastal shallows near Leweton Cultural Village, Espiritu Santo, Vanuatu. Photo: Ash Burgess, November 2017. Used with permission.

According to local lore, women in the Banks Islands have engaged in playful, spontaneous, improvised percussion activities with water 'since time immemorial' (Wessergo 2014, 1). On the islands of Merelava and Gaua, when Mwerlap-speaking women went from the village to the ocean, rivers or creeks to collect food, wash or bathe, they began to recreate in the water the natural sounds around them. Girls from the village, often as young as 5 or 6 years old, would watch, listen, learn, and join in. Over time, this led to the gendered kastom of Etëtung. Wessergo (2014) provides an account of the contemporary development of Etëtung by a group of Mwerlap-speaking women in the 1970s, who began to codify water music sounds with the intention of teaching them to other niVanuatu performers. In Wessergo's version, a key impetus for this codification was the keen interest shown in Etëtung by two European yachting tourists, who 'provided various gifts, and later cash, to the performers to show their appreciation' (in Hayward 2014, 119). Hayward understands 
that this turn of events 'facilitated the transition of a (pre-Western) kastom practice into a contemporary livelihood activity' $(2014,119)$. Nowadays, in its contemporary form, Etëtung features in cultural performances across Vanuatu, including for tourists at high-end resorts:

[v]isitors... can be entertained in resorts by girls and women performing unique ensemble music involving the unison rhythmic beating of hands on water in swimming pools. Performers have developed this bathing and washing game common in many islands into a new tradition with a substantial repertoire including the accompanying of solo and group singing. (Diettrich, Moulin and Webb 2011, 131)

Similar water percussion traditions are found in other parts of Vanuatu and in the Solomon Islands. As for many indigenous and small-island communities around the world, water is central to culture, society, and economy in Leweton. Water is a source of food (fish, shellfish), livelihood (fishing, tourism), trade (via small boats), and leisure (swimming, bathing), as well as being an inspiration and a site for cultural expression through kastom practices such as Etëtung. Hayward characterises the people of Leweton as inhabiting an aquapelago, navigating both freshwater and saltwater aquatic spaces in and around it in a manner 'fundamentally interconnected with and essential to the social group's habitation of land and their senses of identity and belonging' (2014, 115). Perhaps partly because of this centrality of water to life in Leweton, Etëtung has featured prominently in the activities of the Leweton Cultural Village since its inception. The Village also offers visitors traditional weaving, cooking, and storytelling workshops, and the shows that it presents to tourists include a variety of cultural practices including dancing, singing, stringband matto (Melanesian-style string band combined with traditional percussion from the Banks Islands; Dick, 2016), kava-drinking, and food preparation. However, Etëtung is its most iconic attraction.

\section{Climate justice and cultural sustainability in Vanuatu}

Several researchers have observed a certain lack of engagement with climate change concerns among some ni-Vanuatu communities. Warrick found that participants in her research 'did not always have strong views on climate stress or climate change, and did not always consider these problems as priority concerns in the community context' (2009, 59-60). Conway and Mustelin encountered similar attitudes in community-based adaptation projects in rural Vanuatu, where 'climate stress was not always judged to be a priority concern, resulting in low levels of interest in participatory activities' $(2014,339)$. During my field visit to Leweton in late 2017, although I spoke with several community members across a range of ages with awareness of, and concern about, climate change, others indicated limited concern about the matter, or held an attitude of inevitability about the impact of climate change on their lives and those of future generations. Warrick (2009) surmises that the naturally variable climate of Vanuatu may be the primary reason for such views, while Conway and Mustelin $(2014,339)$ reflect that in developing countries like Vanuatu, immediate needs (like sourcing adequate food and clean water) understandably sometimes take priority over long-term risks like climate change. Relatively low levels of expressed concern about climate change among individuals and communities may also be indicative of people and communities adapting over time to changing climatic conditions.

However, in efforts to understand ni-Vanuatu perspectives on climate change, previous experiences of engaging with climate change mitigation and adaptation strategies must also be taken into account. Several such strategies in Vanuatu have taken a top-down approach, and have failed to consider the importance of community and culture to such efforts. Consultation on national climate change adaptation measures, for example, have at times involved only experts and senior 
government officials, and so have not necessarily represented or aligned with the priorities and needs of the communities (Sherman and Ford 2014). Other measures have prioritised the protection of environmental resources over the needs of the local people, 'whose livelihoods and culture are often inextricably linked to these resources' (Warrick 2007, 5). Some strategies, perhaps especially those (like carbon trading programs) that seek to address both environmental and development concerns, may have inhibited effective and socially just climate change mitigation, for example 'by participating in neo-colonial mythologies' (Lohmann 2008, 364; see also White 2017). Inasmuch as these considerations relate to ni-Vanuatu people being enabled and empowered (or not) to actively and meaningfully participate in climate action, they are matters of climate justice (Bond 2012; Thorp 2014). The term climate justice refers not only to the unequal social and geographical causes and impacts of climate change, but also to "principles of democratic accountability and participation, ecological sustainability and social justice and their combined ability to provide solutions to climate change" (Chatterton, Featherstone and Routledge 2013, 606).

Similar moral considerations arise in relation to efforts to support cultural sustainability. Extensive threats to the vitality and viability of cultural expressions across the world, particularly those of indigenous peoples, are closely interrelated with social injustices (Grant 2014), including socioeconomic inequalities, the effects of colonialism, war and displacement of people, Western capitalism, and environmental degradation and destruction. Top-down or outsider-driven strategies attempting to mitigate cultural loss - whether those strategies emanate from the local, regional or international levels - risk perpetuating the very global imbalances of power that led to them in the first place. Time and again, such strategies elicit disengagement or disapproval from local communities, who instead call for greater agency in making their own decisions about the future of their cultural heritage (Schippers and Grant 2016). In this sense, cultural sustainability is intimately interconnected with notions of cultural rights (Weintraub and Yung 2009) and cultural justice (Niezen 2009), and resonates closely with the concepts of climate justice as described above.

These considerations, then, provide a possible context for the reticence of some ni-Vanuatu communities to engage with environmental or cultural sustainability strategies that do not take into account, or that may even undermine, local knowledge and priorities (Warrick 2009). Communitybased initiatives to understand and respond to environmental and/or cultural change are considerably more likely to succeed — not least, because they involve community and respect, and they utilise local knowledge, uphold local knowledge and traditions, encourage communication, and build local capacity (Grant 2014; Richmond and Sovacool 2012). The rest of this article explores one such initiative.

\section{The case of Etëtung}

In drawing on Etëtung to better understand and respond to environmental and cultural changes, the people of Leweton are forging pathways toward cultural and environmental sustainability that are uniquely suited to their circumstances and needs. With Etëtung as a case study, in this section I explore three key ways in which climate justice and cultural sustainability are intertwined in Leweton, with a focus on how they are working in the service of each other. The first way relates to Etëtung embodying traditional cultural and environmental knowledge; the second, to Etëtung as a drawcard for cultural tourism; and the third, to the growing profile of Etëtung in the international climate discourse. While the relationships between climate justice and cultural sustainability in relation to Etëtung extend beyond these three areas, here I choose to focus on these as prominent examples of the challenges and potential for the Leweton community of the interconnectedness of climate justice and cultural sustainability. 


\section{Cultural and environmental knowledge}

Community leader Sandy Sur describes Etëtung as 'a message': 'the sound weaves through the ocean and the land, weaving our stories as it goes. Our stories are told through the water like a book' (interview, November 2017). Hayward (2014) refers to Etëtung as a sonic way of knowing and understanding the world, an acoustemology in Feld's (2012) sense of the term. As the women of Leweton represent in the water the sounds familiar to them through their experience of the world - a dolphin, falling rain on taro leaves, thunder, a waterfall, whale fish, skull fish, certain local species of birds, water ebbing back through the rocks at high tide - they manifest 'localized creative dialogue with the specificity of place' through their performance (Hayward 2014, 117). In Sur's words, 'stories are knowledge, knowledge is culture, and culture is water and land'. In this way, the deep relationship between culture and environment, and between cultural and environmental knowledge, is manifest in each and every performance of Etëtung.

As the world and their experience of the world changes through time, the women explore and introduce new sounds into their practice of Etëtung. In recent years this has led to an expansion of the 'sonic palette' to include new sounds such as 'sogor (the sound of fish chasing baitfish); worworok (rhythmic creek noises) and ne-lea (water flow resonating in cave spaces)' (Hayward 2014, 121). 'Water music is alive', says Martha Rowan Wevales, 'it is nature; we create the sounds that reflect nature, and the sound rises up' (interview, November 2017). One of the younger generation of players, Delite Ron, believes that 'every day the earth is changing; by playing water music we are sharing a message about these changes' (interview, November 2017).

The living, changing practice of Etëtung in Leweton counterbalances tropes of cultural atrophy in Vanuatu. In one national study of nearly 800 people across all provinces, people's knowledge, understanding, and practice of kastom 'as measured through one's understanding of traditional stories, dances, songs, and games passed down for generations' was found to be relatively weak: nearly half ( $47 \%)$ of respondents were found 'deficient' across all categories (Vanuatu National Statistics Office 2012). Dick interprets this as indicating that traditional wisdom, as an aspect of cultural heritage, is at risk from the 'forces of colonisation, globalization and modernity' $(2015,53)$. Climate change may be conceived of as one such force, directly affecting people's lives and livelihoods and therefore also affecting the vitality and viability of cultural expressions. The members of the Leweton community are maintaining the kastom practice of Etëtung and adapting and integrating it into their contemporary lives on Espiritu Santo. They are thereby also proactively counteracting the potentially or actually detrimental effect that cultural and climate injustices may otherwise have on their culture and future.

In Leweton, the integral role of Etëtung in village life both contributes to, and is an indicator of, local strength of kastom and its transmission to future generations. As studies in Vanuatu and elsewhere have shown, cultural participation and cultural strength are correlated with individual and collective wellbeing and resilience (Bolton 2003; Dick and Meltherorong 2011). It therefore seems eminently possible that keeping Etëtung strong may have these kinds of benefits too (a topic ripe for future research). Conversely, two potential consequences of the gradual loss of local traditional environmental and cultural knowledge — such as that contained in Etëtung — include fewer cultural resources for the community to understand, process and respond to climate change; and concomitantly lower resilience to its effects. Indeed, one study of a ni-Vanuatu community of remote Tangoa Island, which is particularly affected by cyclones, found that its members believe themselves to be less resilient to climatic stress than in the past because of the "increasing prevalence of "western" or "modern" values and systems [and] increasing demands for money with increasing integration into the capitalist economy” (Warrick 2007, 18). 
In addition to its roles in reinforcing and maintaining culture and contributing to resilience and wellbeing, Etëtung also serves to strengthen the relationship of the Leweton community to land, water and the natural environment. Researchers have long noted the fundamental importance of the natural world to indigenous ni-Vanuatu: land and water are a physical and socioeconomic resource that sustains life; are inseparably linked with kinships groups and sociocultural identity; and hold 'spiritual and cosmological significance, which underpins the community's relationship with the ancestral world in continuity between the past, present and future' (Ratuva 2010, 53-54). In the words of young performer Vanessa Nilson, 'Water Music lets people know that water is a part of our lives, and a part of us' (interview, November 2017). Those ni-Vanuatu individuals and families who relocated from Gaua and Merelava to Luganville confirm and strengthen their ties to water and land each time they perform Etëtung in the local (Leweton) context, as well as consolidating their cultural relationship to their places of origin. They also reinforce their individual and collective relationship to the world around them: 'The message of Water Music is about the sounds, and the sounds connect us back to nature', says performer Cecelia Lolonun (interview, November 2017). In these ways, through the practice of Etëtung, the people of Leweton counter those forces mentioned above that threaten to jeopardise the strength and health of the relationship between culture and the world around them.

\section{Cultural tourism}

Since its founding a little over a decade ago, Leweton Cultural Village has become a top tourist attraction on the island of Espiritu Santo, and indeed in the whole of Vanuatu, with 53 of 59 reviews on the tourism website Trip Advisor rating the cultural village experience 'excellent' and many referring to it as 'wonderful' or 'magical' (Trip Advisor 2018). Etëtung is a key component of the cultural experience on offer. Recognising that the visual as well as the auditory component of Etëtung is particularly important for tourists, often the women replace their more contemporary dress with traditional grass-woven costumes from Gaua and Merelava, sometimes with armbands and headwear of woven leaves, flowers, coconuts and pandanus (Hayward 2014). Since cruise-ship tourists typically only visit the village for an hour or two, a concrete pool has been constructed within its bounds, eliminating the need for the women (and the tourists) to make the trip down to the ocean or other natural water source for performance. Tourist performances do not only take place within the village, however; the women of Leweton also appear in tourist resorts and at national and regional festivals. These (and other) opportunities afforded by the tourism industry bring an additional purpose to the Leweton villagers' practice of their tradition; offer opportunities to earn an income; provide an incentive for young girls to learn Etëtung; and in all these ways support the vitality and viability of this cultural practice.

Tourism is Vanuatu's largest industry, and along with the natural environment, cultural goods and services are key to its success (Throsby 2015). However, the tripartite relationship between tourism, environment, and culture in Vanuatu is complex. On the one hand, tourism is accelerating environmental degradation to beaches, coral reefs and forests; leading to poorer water quality in lagoons; and resulting in loss of mangroves due to clearance for tourism development (Fien and Passingham 2002; Hall 2001; Sánchez-Quiles and Tovar-Sánchez 2015). In an interview in mid-2017, Sandy Sur was clearly distressed by sustained damage to reefs caused by the cruise liners off the coast of Espiritu Santo, near Leweton, while also acknowledging the irony: these are the same liners that bring tourists to the Leweton Cultural Village, and which enable the Leweton community to share their cultural heritage with international visitors, teach them about the value and meaning of local culture, and educate them about the ramifications for the community of environmental degradation and climate change (interview, August 2017). Diettrich, Moulin and 
Webb refer to ' $[\mathrm{t}]$ he capitalistic thrusts of destination and musical produce working together to support and maintain a power system wherein Islanders are the suppliers of services but seldom the ones who control and reap the power on a global, or even national, level' $(2011,109)$. Klint and colleagues $(2012,247)$ note that dependence on tourism is the greatest in those Pacific Island countries where natural resources are limited and the climate and topography is attractive to tourists, both of which are the case for Vanuatu.

Just as tourism presents various risks to the environment, climate change presents various risks to the tourism industry. Extreme weather events, including those caused by climate change, can have a drastic effect on tourism numbers, and thus on Vanuatu's economic sustainability (Spickett, Katscherian and McIver 2013). The increase in frequency of cyclones, increase in temperatures, and decline in rainfall (Republic of Vanuatu et al. 2007) are increasing the demand for potable water across Vanuatu, and accessing safe and reliable drinking water is an ongoing challenge, particularly in rural areas (WHO 2016). The tourism sector's 'voracious consumption' of water (Klint et al. 2012, 254) therefore presents problems not only to the local population, but also to itself. Further, coral bleaching, coastal inundation and erosion, and other forms of environmental degradation caused by climate change are likely to reduce the attractiveness of Vanuatu to tourists over time (UNDP 2018). Thus, several complex cycles are in motion here: the detrimental environmental effects of climate change inhibit a flourishing of the tourism industry; in turn, this limits the ability of ni-Vanuatu people to promote their cultural products as capital and reap the economic benefits that brings; and the resultant additional challenge to thriving lifestyles and livelihoods impedes the self-determination of ni-Vanuatu individuals and communities in relation to the future of their cultural expressions and practices.

In this sense, when Klint and colleagues recommend that '[a]ll sub-sectors of tourism should have a climate change adaptation plan building on the country's strengths and addressing its vulnerabilities' $(2012,270)$, it seems obvious that such an adaptation plan for cultural tourism would build on Vanuatu's rich cultural and linguistic diversity, and seek to mitigate the vulnerabilities of culture in terms of its susceptibility to the effects of climate change. The Leweton community is advancing this intent through its approaches to cultural tourism. By drawing on aspects of kastom over time as cultural capital that generate 'products' for tourist consumption (Throsby 2015) — both tangible, like dyed woven bags, and intangible, like the auditory-visual experience of Etëtung - the pooled financial returns have enabled improved infrastructure in the village, like new toilets and huts, which bring small improvements to quality of life. The relationship of kastom to industry and economy in this way resonate with the notion of Leweton Cultural Village as a 'transitional society' where 'customary institutions exist side by side and interact in a dynamic way with market forces' (Ratuva 2010, 41).

By positioning Etëtung as a kastom practice that is distinctive and meaningful because of climate change, rather than in spite of it, the Leweton community is responding both culturally and economically to climate justice and cultural sustainability considerations, and responding as such to an uncertain cultural and climate future. 'The sounds of Water Music are still the same, but the meaning of Water Music is different now, because of climate change', says performer Cecelia Lolonun. 'Climate change changes everything about nature and us . . If we keep our culture strong, we can keep our nature alive’ (interview, November 2017).

\section{Participation in the global climate discourse}

Both Dick (2014) and Hayward $(2014,125)$ note the economic and practical advantage of the 'inherent portability' of Etëtung: it can be performed in any waist-deep water and requires little infrastructure or resources beyond the water and the performers' bodies, knowledge and skill. This 
makes overseas performances more economically attractive for festival and event organisers, and means that Etëtung is likely to be more feasible in the context of such events than resource-heavy cultural practices, or those closely tied to a specific site or ritual context. In addition to these economic and practical considerations, the portability of Etëtung means that it is more easily mobilised in the service of climate justice and cultural sustainability, for example through the participation of the Leweton women and broader community in a range of events across diverse national and international contexts. Inasmuch as it features water, Etëtung is not only physically but also psychologically portable: people and cultures around the world, indigenous and nonindigenous, recognise that water is essential for survival. These characteristics seem to be affording Etëtung an increasingly influential role in national and international discussions around cultural sustainability and climate justice.

As the Leweton Cultural Group, women from the Leweton community have performed Etëtung around the world. Over the past decade, they have appeared at the World Expo (Spain), Rainforest World Music Festival (Malaysia), Queensland Music Festival (Australia), Floating Land Festival (Australia), Lukaotem Gud Santo Festival (Vanuatu), and several diplomatic functions of the European Union, as well as at various other events. In collaboration with the Australian label Wantok, the Group has produced the DVD Vanuatu Women's Water Music (2014) to critical acclaim; the product includes a 32-page print and e-booklet describing the genesis and practice of the Water Music. Further, particularly over the last five years or so, Leweton community leader Sandy Sur has profiled Etëtung at international symposia and other events, often in collaboration with Australian researchers Thomas Dick and Leah Barclay (and more recently with the author of this present article). Sur's ongoing commitment to, and leadership in, maintaining and promoting Etëtung are driven by several factors, including his conviction about its cultural importance for the community (as described under 'Cultural and environmental knowledge' above), a recognition of its role as a local socioeconomic resource (as described under 'Cultural tourism'); and, increasingly, awareness of how this practice may play a role in the local and global climate justice movement.

Particularly through Sur's efforts and those of the Leweton Cultural Group, local (Leweton) understandings about the contemporary practice of Etëtung and its relationship to the environment and climate has reached international ears at several iterations of Balance-Unbalance (a conference on art as a catalyst to explore the global environmental crisis); Sonic Environments (the symposium of New Interfaces for Musical Expressions, Australia, 2016), Invisible Places (a symposium on sound, urbanism and sense of place, Portugal, 2017), and Perspectives on Listening (a symposium as part of the project Biosphere Soundscapes, Australia, 2017). Sur's modes of participation in such events are various, from delivering conventional in-person conference papers, to participating in panel discussions via Skype, to even performing a 'virtual opening ceremony' from the village (for Balance-Unbalance 2015 in Arizona, USA) - this latter, a ritual expression of local ni-Vanuatu kastom that seemed to resonate deeply with those physically present at the conference despite Sur's own geographical distance (Dick, personal communication, 6 May 2018). In collaboration with his community and researchers in Australia, Sur is actively exploring the potential for new technologies (like virtual reality) and interdisciplinary collaborations to advance the international reach of Etëtung; to share the message of the interconnectedness of land, water, nature and culture; and to inspire climate action.

Thus, although Hayward $(2014,123,125)$ and Dick $(2015,54)$ both conceive of Leweton's international touring and recording as exporting a world music product for the arts and music festival and film circuits, the recent wider profiling of Etëtung has explicitly begun to serve cultural and climate justice functions too. As members of the Leweton community travel nationally and 
internationally to perform and share their knowledge of Etëtung, they are informing and educating listeners and audiences about the deep relationships between people, culture, the natural world, environmental change and climate change. 'Water Music is my identity, my culture', says young performer Vanessa Nilson; 'I hope that one day Water Music will teach people overseas about Vanuatu, and tell them about changes in the lives of people and the environment in Vanuatu' (interview, November 2017). The participation of indigenous people is essential to achieving fairness in political and social solutions to climate change (Adger et al. 2006); through Etëtung, the members of the Leweton community are contributing their voices to the global climate discourse to a degree that remains egregiously inaccessible to other indigenous, minority, and 'minoritised' peoples around the world. In this way, the Leweton community is advancing toward climate justice for themselves and others.

\section{Reflections and implications}

The three themes addressed above - considerations of the cultural and environmental knowledge contained in Etëtung; of the relationship between Etëtung, cultural tourism, and climate change; and of Etëtung enabling greater participation in the international climate discourse-loosely align with Dick's conceptualisation of the Leweton community representing itself 'locally as an Indigenous community, nationally as an iconic cultural performance and tourist spectacle and internationally as artists, dancers and musicians' $(2015,54)$. This multi-layered nature of Etëtung-related activities is affording the Leweton community the opportunity to advance cultural sustainability and social justice concerns across similarly multi-layered contexts.

At the local level, for example, the cultural activities of the Leweton community are proving a means for its members to learn about kastom practices including Etëtung; to maintain and transmit these cultural practices across generations; to consolidate their relationship to the world around them; and to acknowledge and process, in culturally appropriate ways, local changes to culture, environment and climate. Furthermore, these activities are motivating other communities in the Banks Islands group and beyond to learn more about, and renew their practice of, kastom activities, including Etëtung. Dick reports of several further groups of women now performing Water Music traditions, and the 'pride and pleasure amongst the Leweton community based on the fact that people in the Banks Islands are performing this music again' $(2015,54)$.

At the national and international levels, the Leweton community's practice of Etëtung is instructive amid concerns (outlined above) that some national and international climate change adaptation strategies are not only likely to be ineffectual but, even worse, may be entrenching existing power imbalances. It stands in contrast with those efforts that target ecological and cultural devastation through protective or dominant measures, some of which may in fact be restricting local and/or national capacity to deal with the core issues at hand. It also differs from some arts-based environmental projects in that it is fully initiated and driven by the community, to the community's own ends. The very nature of Etëtung as an expression of culture and manifestation of cultural knowledge makes it a powerful tool in both climate justice and cultural justice efforts: in both regards, it is persuasive and compelling to outsiders - tourists, festival audiences, or governmentwhile dispensing with any semblance of the force or dominance that characterises many other climate change adaptation strategies, in Vanuatu and elsewhere.

\section{Acknowledgements}

Thanks to community leader Sandy Sur and all the members of the Leweton community, especially Margaret Lolonun for interpreting and research assistance. Thanks also to Thomas Dick, Leah Barclay, and Ash Burgess for facilitating community connections, providing fieldwork support, and 
giving feedback on a draft of this article. Anonymous reviewers also provided helpful suggestions on an earlier version. This research was funded by a GU Arts Education Law research grant (2017).

\section{References}

Adger, W. Neil, Jon Barnett, Katrina Brown, Nadine Marshall and Karen O'Brien. 2013. "Cultural

Dimensions of Climate Change Impacts and Adaptation." Nature Climate Change 3 (2): 112-7.

Adger, W. Neil, Jouni Paavola, Saleemul Huq and M.J. Mace. 2006. Fairness in Adaptation to Climate Change. Cambridge: MIT Press.

Bolton, Lissant. 2003. Unfolding the Moon: Enacting Women's Kastom in Vanuatu. Honolulu: University of Hawai'i Press.

Bond, Patrick. 2012. Politics of Climate Justice. Paralysis Above, Movement Below. Cape Town: University of Kwa Zulu Natal Press.

Chatterton, Paul, David Featherstone and Paul Routledge. 2013. "Articulating Climate Justice in Copenhagen: Antagonism, the Commons, and Solidarity." Antipode 45 (3): 602-20.

Conway, Declan and Johanna Mustelin. 2014. "Strategies for Improving Adaptation Practice in Developing Countries." Nature Climate Change 4 (5): 339-42.

Corner, Adam, Ezra Markowitz and Nick Pidgeon. 2014. "Public Engagement with Climate Change: The Role of Human Values." Wiley Interdisciplinary Reviews: Climate Change 5 (3): 411-22.

Dick, Thomas. 2014. "Vanuatu Water Music and the Mwerlap Diaspora: Music, Migration, Tradition, and Tourism." AlterNative: An International Journal of Indigenous Peoples 10 (4): 392-407.

Dick, Thomas. 2015. "Alternative Approaches to Well-being and Engagement in Vanuatu."Australasian Psychiatry 23 (6): 52-4.

Dick, Thomas. 2016. "Performing Place: Tourism and Touring with the Leweton Cultural Village." Journal de la Société des Océanistes 142-143: 39-54.

Dick, Thomas and Marcel Meltherorong. 2011. "Dovetailing Discourses of Emergent Resilience in Vanuatu." In Songs of Resilience, edited by Andy Brader, 97-120. Newcastle: Cambridge Scholars Press.

Diettrich, Brian, Jane Freeman Moulin and Michael Webb. 2011. Music in Pacific Island Cultures: Experiencing Music, Expressing Culture. New York: Oxford University Press.

Feld, Steven. 2012. Sound and Sentiment. Philadelphia: University of Pennsylvania Press.

Fien, John and Steve Passingham. 2002. "Pacific Star: Community Theatre as Environmental Learning in Vanuatu." Australian Journal of Environmental Education 18: 63-70.

Grant, Catherine. 2014. Music Endangerment. New York: Oxford University Press

Hackmann, Heide, Suzanne Moser and Asuncion Lera St. Clair. 2014. "The Social Heart of Global Environmental Change." Nature Climate Change 4: 653-5.

Hall, Michael. 2001. "Trends in Ocean and Coastal Tourism: The End of the Last Frontier? ." Ocean \& Coastal Management 44 (9-10): 601-18.

Hayward, Philip. (2014). "Sounding the Aquapelago: The Cultural-Environmental Context of ni-Vanuatu Women's Liquid Percussion Performance." Perfect Beat 15 (2): 113-27.

IPCC (Intergovernmental Panel on Climate Change). 1997. "The Regional Impacts of Climate Change". https://www.ipcc.ch/pdf/special-reports/spm/region-en.pdf

IPCC. 2007. "Climate Change 2007: Synthesis Report." https://www.ipcc.ch/pdf/assessmentreport/ar4/syr/ar4_syr_full_report.pdf

Klint, Louise Munk, Emma Wong, Min Jiang, Terru Delacy, David Harrison and Dale Dominey-Howes. 2012. "Climate Change Adaptation in the Pacific Island Tourism Sector: Analysing the Policy Environment in Vanuatu." Current Issues in Tourism 15 (3): 247-74.

Lohmann, Larry. 2008. "Carbon Trading, Climate Justice and the Production of Ignorance: Ten eExamples." Development 51, no. 3: 359-65.

Niezen, Ronald. 2009. Rediscovered Self: Indigenous Identity and Cultural Justice, vol. 57. McGill-Queen's Press-MQUP. 
Ratuva, Steven. 2010. "Back to Basics: Towards Integrated Social Protection for Vulnerable Groups in Vanuatu." Pacific Economic Bulletin 25 (3): 40-64.

Republic of Vanuatu. 2007. "Vanuatu National Adaptation Programme of Action (NAPA) Official

Document.” http://www.adaptation-undp.org/resources/naps-least-developed-countries-ldcs/vanuatunational-adaptation-programme-action-napa

Richmond, Noah and Benjamin Sovacool. 2012. "Bolstering Resilience in the Coconut Kingdom: Improving Adaptive Capacity to Climate Change in Vanuatu." Energy Policy 50: 843-8.

Sánchez-Quiles, David and Antonio Tovar-Sánchez. 2015. “Are Sunscreens a New Environmental Risk Associated with Coastal Tourism?” Environment International 83: 158-70.

Schippers, Huib and Catherine Grant, eds. 2016. Sustainable Futures for Music Cultures: Towards an Ecology of Musical Diversity. New York: Oxford University Press.

Sherman, Mya and James Ford. 2014. "Stakeholder Engagement in Adaptation Interventions: An Evaluation of Projects in Developing Nations." Climate Policy 14 (3): 417-41.

Simons, Gary F. and Charles D. Fennig, eds. 2018. Ethnologue: Languages of the World. $21^{\text {st }}$ ed. Dallas, Texas: SIL International. http://www.ethnologue.com

Spickett, Jeffrey, Dianne Katscherian and Lachlan McIver. 2013. "Health Impacts of Climate Change in Vanuatu: An Assessment and Adaptation Action Plan." Global Journal of Health Science 5 (3): $42-$ 53.

Tanguay, Jamie. 2015. "Alternative Indicators of Wellbeing for Melanesia: Cultural Values Driving ublic Policy." In Making Culture Count: The Politics of Cultural Measurement, edited by Lachlan MacDowall, Marnie Badham, Emma Blomkamp and Kim Francis Dunphy, 162-172. London: Palgrave Macmillan.

Thorp, Teresa M. 2014. Climate Justice: A Voice for the Future. London: Palgrave Macmillan.

Throsby, David. 2015. "Development Strategies for Pacific Island Economies: Is There a Role for the Cultural Industries?" Asia \& the Pacific Policy Studies 2 (2): 370-82.

Trip Advisor. 2018. Magical Water Music Experience (Luganville): Top Tips Before You Go. https://www.tripadvisor.com.au/Attraction_Review-g1207993-d4756137-ReviewsMagical_Water_Music_Experience-Luganville_Espiritu_Santo.html\#REVIEWS

UNDP (United Nations Development Program). 2018. "Vanuatu National Adaptation Programme of Action." http://adaptation-undp.org/projects/vanuatu-national-adaptation-programme-action-napa.

UNICEF (United Nations Children's Fund) . 2016. "Cyclone Pam: One Year On.” https://reliefweb.int/report/vanuatu/unicef-fast-facts-cyclone-pam-one-year-march-2016

Vanuatu National Statistics Office. 2012. "Alternative Indicators of Wellbeing for Melanesia: Vanuatu Pilot Study Report.” https://vnso.gov.vu/surveys/census-2009-tables/doc_download/193-well-beingsurvey-2012

Vanuatu Women's Water Music. 2014. [DVD]. Performed by members of the Leweton Mwerlap community and directed by Tim Cole. Melbourne, Australia: Wantok Music.

Verisk Maplecroft. 2015. Natural Hazards Risk Atlas. https://maplecroft.com/portfolio/newanalysis/2015/03/04/56-100-cities-most-exposed-natural-hazards-found-key-economies-philippinesjapan-china-bangladesh-verisk-maplecroft/

Warrick, Olivia. 2007. "Development, Forest Conservation and Adaptation to Climate Change: A Case for Integrated Community-Based Sustainability in Rural Vanuatu." Paper presented at the 2007 ANZSEE Conference: Reinventing Sustainability: A Climate for Change, July 3-6, Queensland, Australia.

Warrick, Olivia. 2009. "Ethics and Methods in Research for Community-Based Adaptation: Reflections from Rural Vanuatu." Participatory Learning and Action 60: 76-87.

Weintraub, Andrew and Bell Yung, eds. 2009. Music and Cultural Rights. Chicago and Urbana, IL: University of Illinois Press.

Wessergo, Warren Wevat. 2014. "The History of the Magical Water Music." Essay in Booklet Accompanying Vanuatu Women's Water Music DVD. 
White, Julianna. 2017. Global Carbon Tax Would Increase Undernourished by 80-300 Million; Alternative Strategies Protect Food Security. https://ccafs.cgiar.org/research-highlight/global-carbon-tax-wouldincrease-number-undernourished-80-300-million-2050\#.WlquI6iWaM8 (accessed 14 January 2018).

WHO (World Health Organisation). 2016. Sanitation, Drinking Water and Health in Pacific Island Countries: 2015 Update and Future Outlook. Geneva, Switzerland: World Health Organisation. http://iris.wpro.who.int/bitstream/handle/10665.1/13130/9789290617471_eng.pdf. 